\title{
Natural products originated from the oxidative coupling of tyrosine and tryptophan: biosynthesis and bioinspired synthesis
}

\author{
Shanyu Tang, ${ }^{[a]}$ and Guillaume Vincent ${ }^{*[a]}$ \\ Dedication ((optional))
}
[a] Ms. Shanyu Tang and Dr. Guillaume Vincent
Institut de Chimie Moléculaire et des Matériaux d'Orsay (ICMMO)
Université Paris-Saclay, CNRS
91405 Orsay, France
E-mail: guillaume.vincent@université-paris-saclay.fr

Supporting information for this article is given via a link at the end of the document.((Please delete this text if not appropriate))

\begin{abstract}
The oxidative coupling of tyrosine and tryptophan units is a pivotal step in the total synthesis of some peptide-derived marine and terrestrial natural products such as the diazonamides, azonazine and tryptorubin A. This review details the biosynthesis and bioinspired synthesis of natural products with such structures. Through this review, we focused on the challenges of the synthesis of these natural products and the innovative solutions adopted by synthetic chemists.
\end{abstract}

\section{Introduction}

Amino acid-derived natural products are widespread in nature. Tyrosine and tryptophan are common amino acids and therefore usually appear in the structure of natural peptides. Apart to classical amide bonds, few of these natural products also display an additional linkage between the phenol part of a tyrosine (1a) and the indole part of a tryptophan (2a, Figure 1). Biosynthetically,

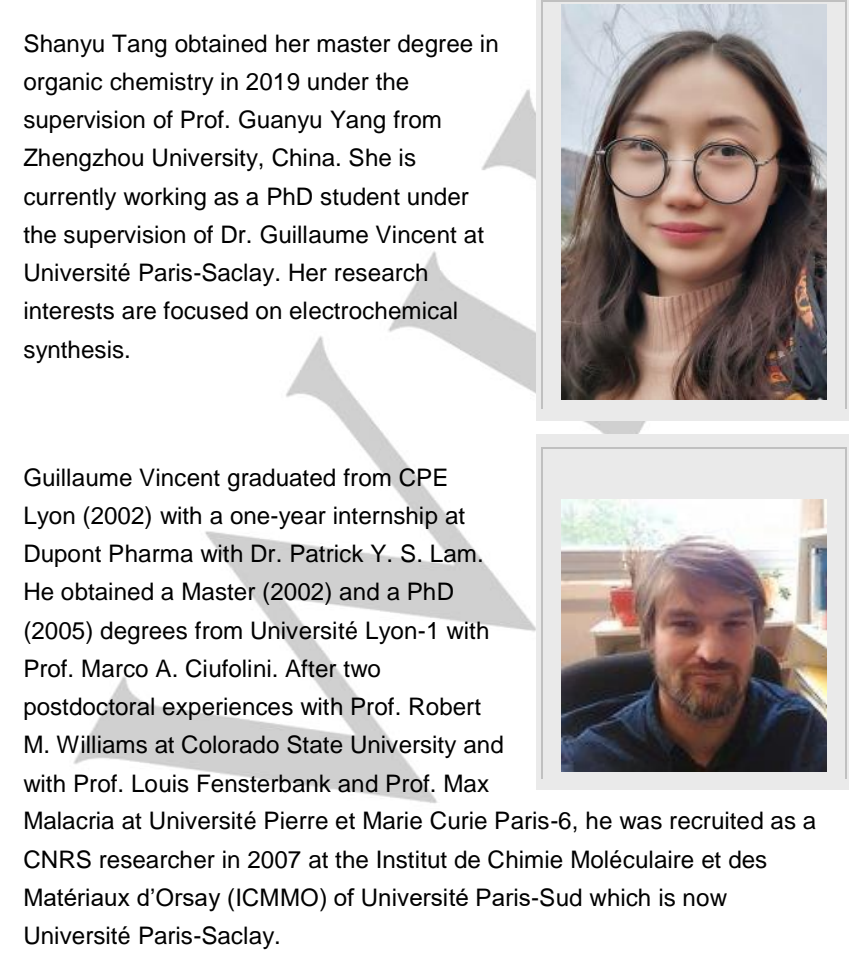

these additional bonds arise from an oxidative cyclization. ${ }^{[1]}$ They could be produce by marine organisms or by terrestrial fungus. The synthesis of such molecules has indeed attracted widespread attention from synthetic chemists, not only because of the challenging structure, but also for the biological activity of some of these compounds.

Understanding their biosynthesis is important to help chemists designing simplified and efficient synthetic routes towards these natural products.

Therefore, we will review the biosynthesis of diazonamide A (3a), azonazine (4) and tryptorubin A (5) and their related bioinspired syntheses via oxidative couplings of tyrosine and tryptophan units involving the formation of a carbon-heteroatom bond.

Besides, the natural products presented in this minireview, it should be noted that other natural entities present a link between the benzene part of the indole of a tryptophan and the orthoposition of the phenol of tyrosine. It is the case of TMC-95 A-D $D^{[2,3]}$ (6a-d, produced by the fermentation broth of Apiospora montagnei Sacc Tc. 1093 isolated from soil samples) and of some proteins 7 that are composed of covalently crosslinked aminoacid side-chains. ${ }^{[4]}$

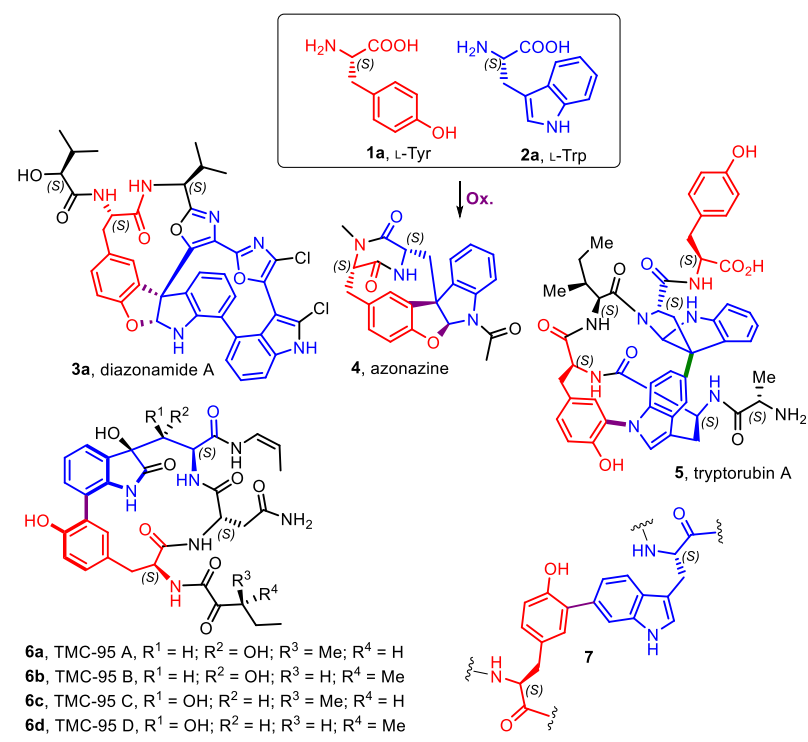


Figure 1. Natural products biosynthetically derived from the oxidative coupling of L-tyrosine and L-tryptophan residues.

In the context of the total synthesis of the TMC-95 natural products, the $\mathrm{C}-\mathrm{C}$ biaryl bond linking the tyrosine and tryptophan units are usually formed by a Suzuki coupling in the context of total synthesis. ${ }^{[3]}$

\section{Diazonamide A}

Diazoamide $A$ is a marine secondary metabolite which displays low nanomolar cytotoxicity against several tumoral cell lines. It was isolated in 1991 by Fenical from the ascidian Diazona angulata (originally attributed to Diazona chinensis) along with diazonamide $\mathrm{B}^{\left[{ }^{[5]}\right.}$ Their original structures were determined by $\mathrm{X}$ ray crystallography of a derivative of diazonamide $B$. The proposed structure $\mathbf{8}$ of diazonamide A included notably a linkage between the phenol of a tyrosine and a hydroxydihydrobenzofurane, as well as a sequence of two oxazoles and an indole (Figure 2). The antitumoral potential and the rare and particular structure of diazonamide $\mathrm{A}$ has attracted the wide attention of synthetic chemists. However, in 2001, when the group of Harran completed the first total synthesis of the proposed structure, ${ }^{[6]}$ it was found to be different from the natural product. After reinterpretation of the X-ray crystallography data and additional 2D-NMR experiments, Harran proposed the alternative structures $\mathbf{3 a}$ and $\mathbf{3} \mathbf{b}$ of diazonamides $\mathrm{A}$ and $\mathrm{B}$, in which the difference with the original scaffold is the presence of a central benzofuroindoline instead of the 3-aryl-2-hydroxydihydrobenzofurane. ${ }^{[7]}$ The benzofuroindoline moiety is also found in other natural products such as bipleiophylline, pleiocraline or pleiocorine. ${ }^{[8,9]}$ Moreover Diazonamide A possesses a hydroxyisovaleric acid unit instead of a valine at one end of the molecule. In 2008, Reyes isolated, from Diazona sp., diazonamides C-E $(3 c-3 e)$ which possess the same backbone of diazonamides $A$ and $B \cdot{ }^{[10]}$
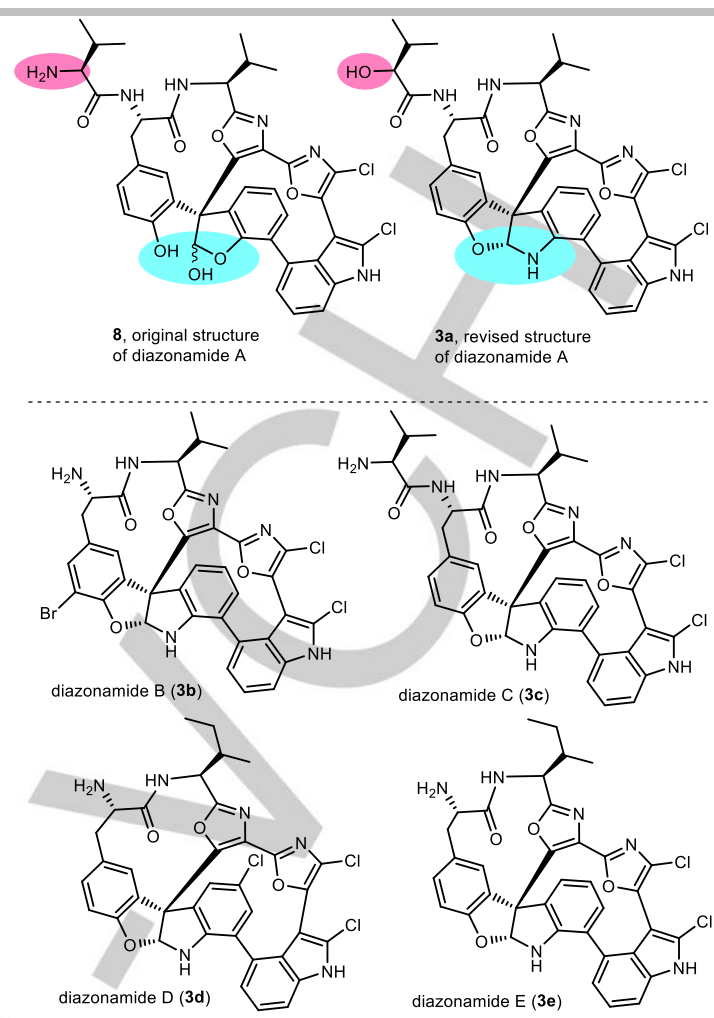

Figure 2. Structures of diazonamides A-E (3a-e).

After the correction of the general structure of the diazonamides, it seems plausible that they have for biosynthetic origin the assembly of four amino-acids: one tyrosine (1a), two tryptophanes (1a) and one valine (9a) as well as a (S)- $\alpha$-hydroxy isovaleric acid $\mathbf{1 0}$ (Figure 2).

The corresponding L-Tyr-L-Val-L-Trp-L-Trp tetrapeptide 11 would be involved in several oxidation events involving the tryptophan units: oxidation at the $\alpha$-position of the indoles to form the two oxazoles and formation of the biaryl bond between the two indoles. Importantly, the oxidative macrocyclization between the tyrosine and one of the tryptophan would form the benzofuroindoline core 12 via formation of a C-C bond between the ortho-position of the phenol and the C3-position of the indole, as well as a C-O bond between the oxygen of the phenol and the C2-position of the indole. This reaction involves the union of two nucleophilic entities and from a mechanistic point of view several scenarios are possible: either the phenol or the indole could be oxidized into a cationic intermediate (A or $\mathbf{B}$ ) on which the other nucleophile, respectively the indole or the phenol, could add. However, an enzymatic-mediated radical process seems more reasonable. ${ }^{[1]}$ Both the indole and the phenol could be oxidized via two singleelectron transfers (SET) into radical species (C) that would be coupled. Alternatively, only the indolyl radical D or phenoxy radical $\mathbf{E}$ is formed and the second SET happens after the reaction of this radical with the other heteroaromatic unit. 

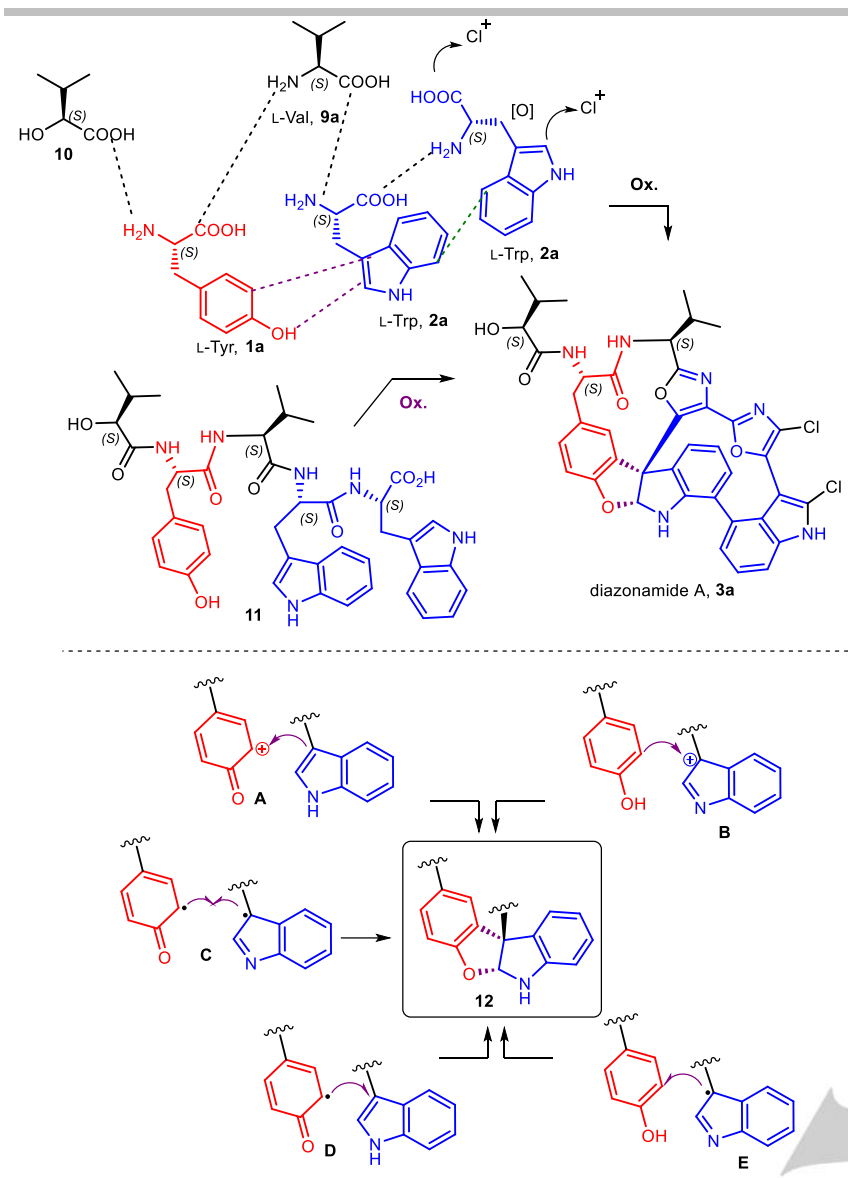

Figure 3. A plausible biosynthetic origin of diazonamide A (3a).

In 2002, the group of Nicolaou was the first to report the total synthesis of the revised structure of diazonamide A via the acidmediated addition of protected tyrosine methyl ester $\mathbf{1 b}$ to 3 hydroxy-3-oxazolyl-2-oxindole $\mathbf{1 3}$ which can be seen as a preoxidized tryptophan surrogate leading to 14 without diastereocontrol (Scheme 1). ${ }^{[11]}$ In 2007 Magnus reported a related intramolecular approach in which the tyrosine residue is attached to the valine unit in 15. ${ }^{[12]}$ Conversion of the hydroxyl group on the oxindole into a chloride, followed by removal the silyl group on the phenol of tryrosine, led to the formation of $\mathrm{O}$-aryl ether 16 as a 1:1 mixture of two epimers. Upon heating the latter, $O$ to $C$ aryl migration occurred delivering overall 3-aryloxindole 17 in $70 \%$ along with $30 \%$ of its epimer. An intermediate of the Nicolaou synthesis was then intercepted from 17.

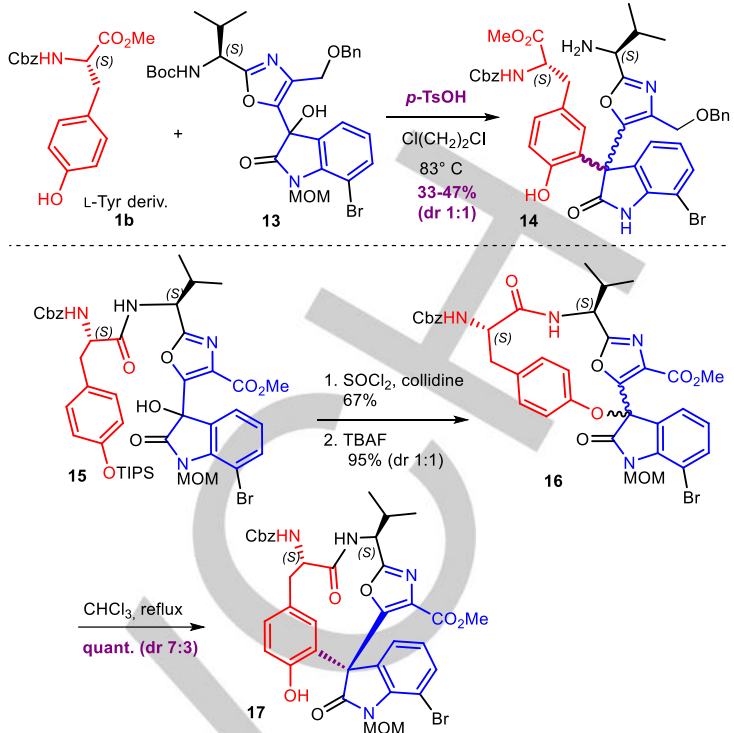

Scheme 1. Key steps of the first total synthesis of diazonamide A by Nicolaou top, 2002) and the formal synthesis of Magnus (bottom, 2007).

Shortly after the synthesis of Nicolaou (and before the Magnus formal synthesis), Harran proposed a truly bioinspired synthetic route toward diazonamide A from amino-acid derivatives (Scheme 2). ${ }^{[13]}$ Dipeptide 18 obtained from racemic bromotryptophan $\mathbf{2 b}$ with $\mathrm{N}-\mathrm{Cbz}-\mathrm{L}-\mathrm{valine} \mathbf{9 b}$ was oxidized with DDQ to form the oxazole ring of $19 .{ }^{[14]}$ Further peptidic coupling with $\mathrm{N}$ sulfonyl-L-tyrosine 1c afforded key precursor 20.

The stage was set to perform the biomimetic oxidative union of the phenol and indole moiety. Accordingly, oxidation of $\mathbf{2 0}$ with the hypervalent iodine reagent $\mathrm{Phl}(\mathrm{OAc})_{2}$, underwent macrocyclization to directly produce benzofuroindoline 21 . The free phenol of tyrosine would exchange with an acetate of $\mathrm{Phl}(\mathrm{OAc})_{2}$ to generate highly electrophilic intermediate $\mathbf{F}$, which would be captured by the nucleophilic position of the indole to form the C-C bond. ${ }^{[15]}$ Then, cyclohexanedienone would add to the adjacent iminium $\mathbf{G}$ to provide the hemiaminal of $\mathbf{2 1}$ via formation of the $\mathrm{C}-\mathrm{O}$ bond. The stereocontrol induced by tyrosine and valine residues allows the formation of the quarternary carbon in a 3:1 ratio of diastereoisomers in favour of the desired configuration. The fact that it is the phenol that is oxidized rather than the indole is deducted from the formation of spirocyclic cyclohexanedienone $\mathbf{2 2}$ as the major by-product via intramolecular addition of the carbonyl of tyrosine into electrophilic intermediate $\mathbf{F}$. 


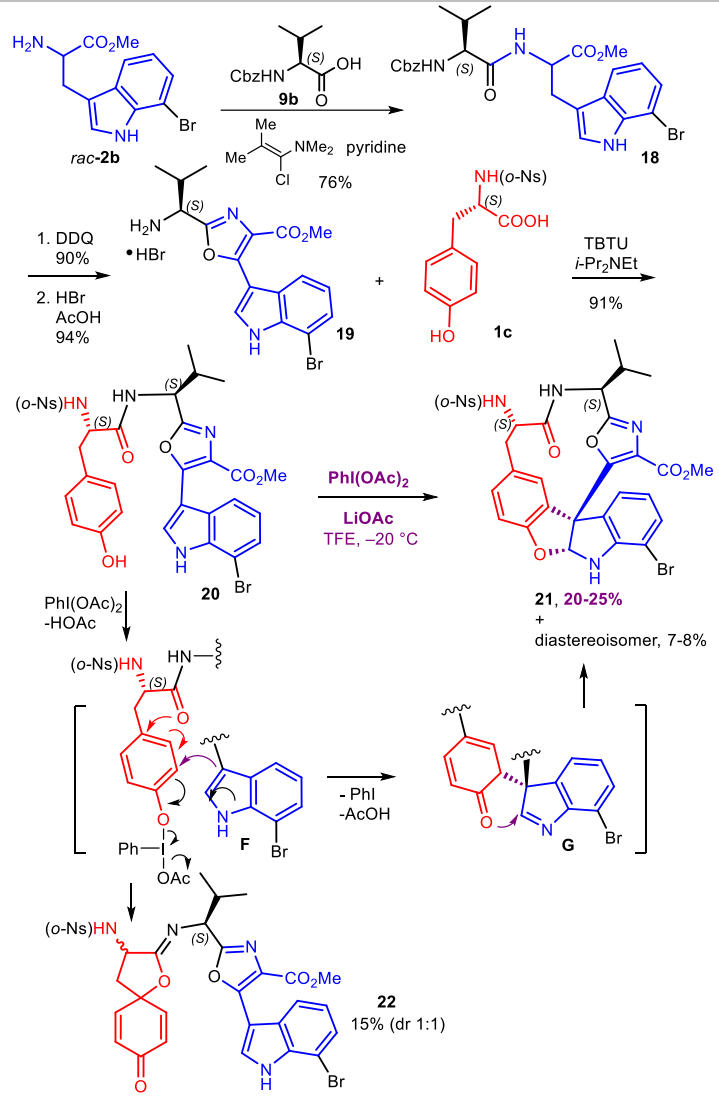

Scheme 2. Bioinspired oxidative coupling of tyrosine and tryptophan residues by Harran (2003).

Formation of the second macrocyle of the natural product was then undertaken (Scheme 3). Peptidic coupling of macrolactam 21 with hydroxy-tryptamine derivative 23 yielded 24. Benzylic oxidation and dehydration provided bis(oxazolyl) indole 25 . The formation of the biaryl bond between the benzene parts of the indoles of the two tryptophan units was achieved via a photocyclization. The degassed lithium phenoxide solution obtained by dissolving compound $\mathbf{2 5}$ in an aqueous solution of $\mathrm{CH}_{3} \mathrm{CN}$ containing $\mathrm{LiOH}$ was photolyzed at $300 \mathrm{~nm}$ to atroposelectively produce biaryl $\mathbf{2 6}$ with a good yield. It is supposed that the reaction proceeds via a photoinduced electron transfer from the phenoxide to the bromoarene. The generated bis-radical intermediate $\mathbf{H}$ could lead, after elimination of bromide, to the desired biaryl bond. The phenolic hydroxy group of $\mathbf{2 6}$ was then removed via reduction of its corresponding triflate. Finally, bis-chlorination and introduction of (S)-a-hydroxy isovaleric acid $\mathbf{1 0}$ on the tyrosine residue delivered diazonamide A (3a).

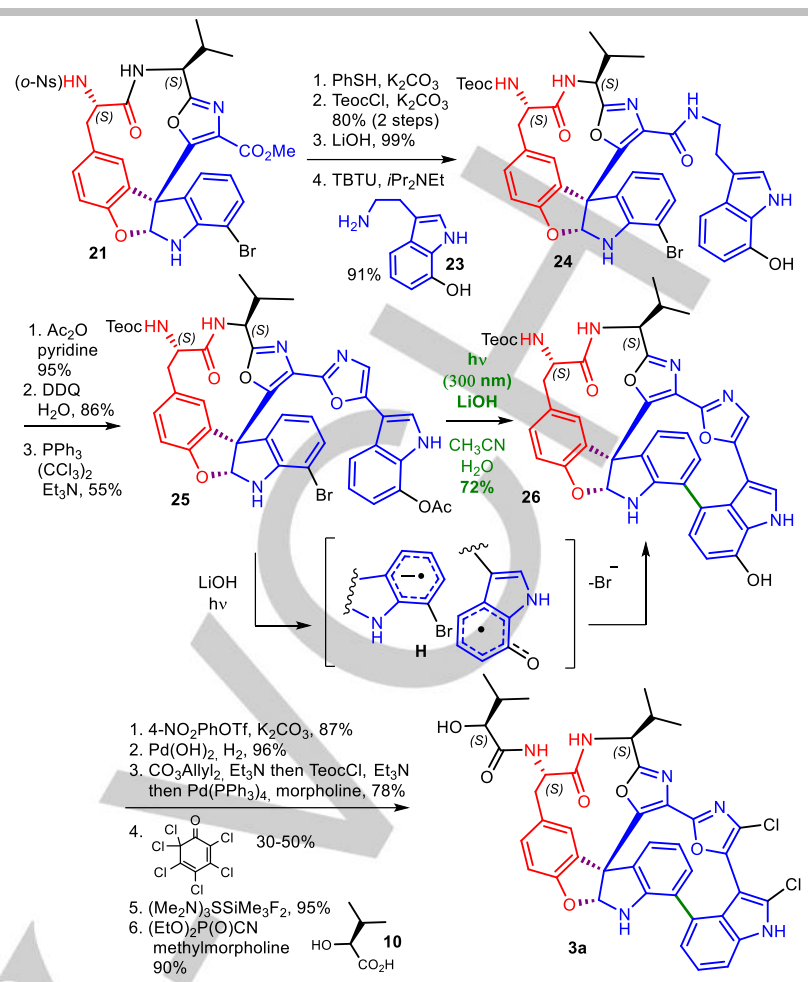

Scheme 3. Completion of the total synthesis of diazonamide A by Harran (2003).

After the two first total syntheses of this natural product by Nicolaou, and Harran and beside the formal synthesis of Magnus, other total or formal syntheses were reported by Nicolaou, Sammakia, MacMillan and Moody in a less bioinspired manner for the assembly of the tyrosine and tryptophan units. ${ }^{[16,17]}$ Konopelski also reported an interesting stereoselective C-arylation of an oxindole apparented to tryptophan with a tyrosine-derived arlylead(IV) reagent. ${ }^{[18]}$

Diazonamide A proved to have a very promising therapeutic potential as an antitumoral agent via interaction with microtubules. ${ }^{[19]}$ In addition to inhibiting several cancer cell lines at low nanomolar concentrations, diazonamide $A$ does not have the neurotoxicity usually observed for microtubule-targeting agents. ${ }^{[20]}$ This observation fosters research programs to determine the synthesis of a large numbers of analogs for SAR study and in particular from Joyant Pharmaceuticals who was cofounded by Harran. ${ }^{[21]}$ Eventually, DZ-2384 (27) emerged from Diazon Pharma, also co-founded by Harran, as a very potent analog of diazonamide $\mathrm{A}$ in cancer chemotherapy with a high safety margin. While it binds to tubulin on the same domain as the vinca alkaloids, it induces a distinctive effect which preserves nondividing cells. ${ }^{[22]}$ This simplified analog lacks the indole between one of the oxazole and the other indole.

One of the main drawback of the $\mathrm{Phl}(\mathrm{OAc})_{2}$-mediated oxidative coupling is the formation of spirocyclic dienone 22 which is difficult to separate from the desired benzofuroindoline 21. This problem was circumvented by Harran and Joyant Pharmaceuticals during the production of analogs of diazonamide A via the deployment of electrochemistry. [21a]

This electrochemical method was detailed in 2015, by Harran and scientists from Joyant Pharmaceuticals and Paraza Pharma for the scalable synthesis of DZ-2384 (27, Scheme 4). ${ }^{[23]}$ To test the electrochemical oxidative cyclization, the authors synthesized 
compound 29 via coupling between N-Cbz-L-tyrosine 1d and compound 28 which was raised from oxidation of a tripeptide constituted of $t$-leucine, 5 -fluorotryptophan and serine residues.

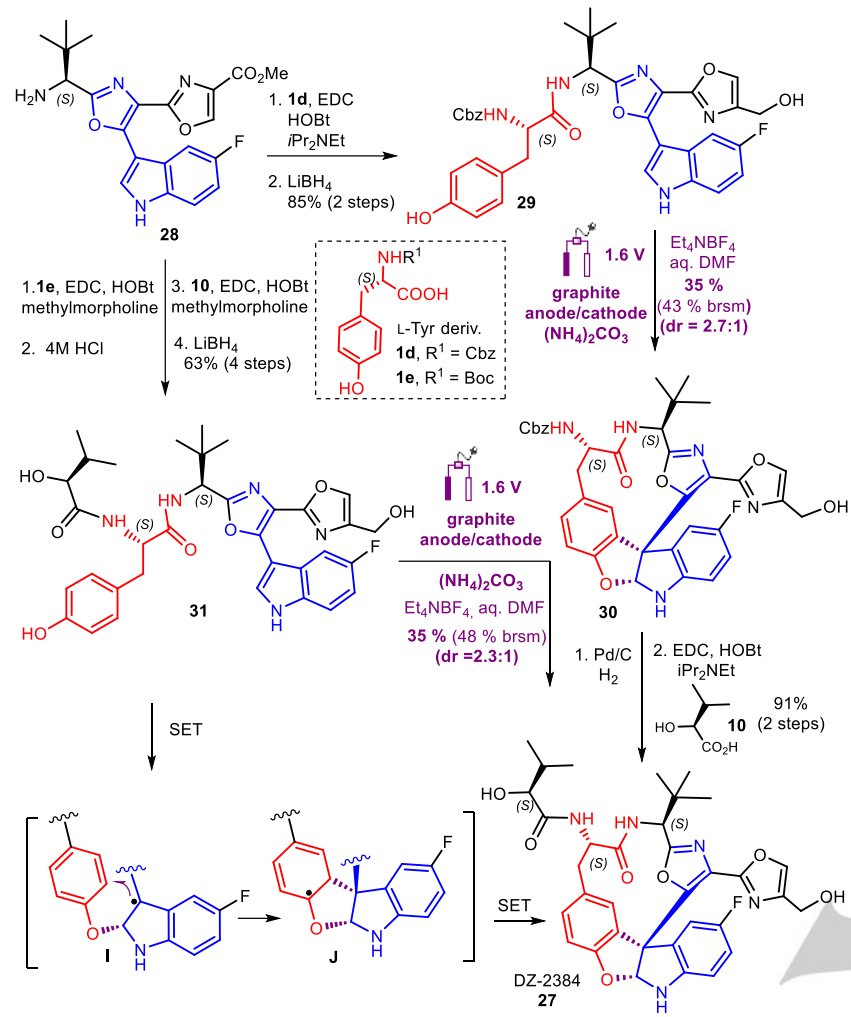

Scheme 4. Two concise syntheses of DZ-2384 employing an electrolytic macrocyclization by Harran, Joyant Pharmaceuticals and Paraza Pharma (2010-2015)

Substrate 29 was then electrolyzed in an undivided cell open to air surrounded by concentric rings of graphite rods which acts as anodes and cathodes at a constant cell potential of $+1.6 \mathrm{~V}$ at ambient temperature in aqueous DMF with addition of solid $\left(\mathrm{NH}_{4}\right)_{2} \mathrm{CO}_{3}$ in batches and in presence of tetraethylammonium tetrafluoroborate as electrolyte. Impressively, the macrocyclization went smoothly on 60 grams of 29 and 21 grams of 30 were obtained in $35 \%$ yield $(43 \%$ brsm) with a $2.7: 1$ diasteromeric ratio without the formation of the undesired spirocyclic dienone observed with $\mathrm{Phl}(\mathrm{OAc})_{2}$. Cyclic voltammetry experiments suggested that it is the indole moiety which is oxidized into radical intermediate I via single electron transfer at the anode. I could then react with the phenol and a second SET event from $\mathbf{J}$ would produce benzofuroindoline. This distinct mechanism from the $\mathrm{Phl}(\mathrm{OAc})_{2}$ oxidation explains that a spirodienone is not formed. The two diastereoisomers were separated after the subsequent removal of the $\mathrm{Cbz}$ group. Introduction of the 2-hydroxyisovaleric acid moiety then delivers 20 grams of DZ-2384 (27). Because it is necessary to perform a chromatography on silica gel after the electrolysis, the author hoped to perform the electrolysis at the last step to delay this purification. Therefore, the electrolysis was performed on $740 \mathrm{mg}$ of $\mathbf{3 1}$ which already contains the 2-hydroxyisovaleric acid residue and was obtained in four steps without chromatography from 28. Application of the same electrochemical conditions allowed to obtain directly a $35 \%$ yield (48\% brsm) of DZ-2384 (27) as a 2.3:1 mixture with its diastereoisomer. In summary, the authors were able to obtain drug candidate DZ-2384 in 13 steps with a total yield of $5.7 \%$ from tert-leucine.

\section{Azonazine}

Azonazine (4) is another tyrosine-tryptophan-containing marine natural product that contains a benzofuroindoline core. In 2010, Crews and co-workers reported the isolation of this unique hexacyclic dipeptide from a Hawaiian marine sediment-derived fungus, Aspergillus insulicola. ${ }^{[24]}$ Structurally, the benzofuroindoline ring system bearing a quaternary center at its ring junction, indeed presents similarity to the core of the diazonamides (3a-e). Noteworthy, the tyrosine-derived nitrogen is methylated and the indolic nitrogen is acetylated. In 2013, following the total synthesis of ent-azonazine by Yao, the relative stereochemistry of azonazine was revised from $\mathbf{3 2}$ to $\mathbf{4}$ (Figure 4). ${ }^{[25]}$ The natural product arose from L-tryptophan and L-tyrosine instead of their D-enantiomers as initially proposed, while the absolute stereochemistry at the ring junction of the benzofuroindoline is the same as the proposed structure. This absolute stereochemistry of the benzofuroindoline part is opposed to the one of the diazonamides, while they both have Ltyrosine and L-tryptophan as starting points. Crews proposed that, biosynthetically, diketopiperazine $\mathbf{3 3}$ derived from tyrosine and tryptophan, would undergo an oxidative cyclization in a similar fashion as for diazonamide $A$.

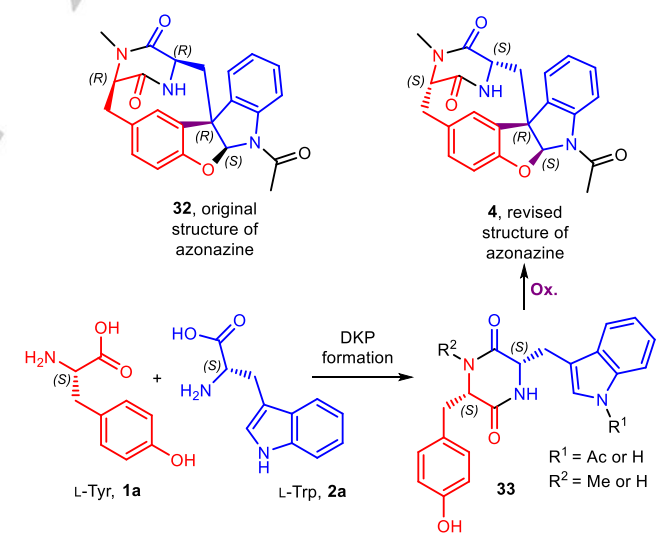

Figure 4. Azonazine and its plausible biosynthesis

Inspired by the total synthesis of diazonamide A by Harran, ${ }^{[13]}$ the group of Yao thought to deploy a bioinspired oxidative cyclization between the indole and the phenol of diketopiperazine ent-33 to construct the highly strained benzofuroindoline-containing 10 membered ring system. Diketopiperazine ent-33 was obtained from D-tryptophan 2c and D-tyrosine 1f derivatives. After screening various conditions with hypervalent iodine(III) reagents, it was found that 2 equivalents of $\mathrm{Phl}(\mathrm{OAc})_{2}$ in trifluoroethanol at $-15^{\circ} \mathrm{C}$ allowed to obtain in modest yields the overoxidized hexacyclic skeleton of azonazine as two diastereoisomers $34 \mathrm{a}$ and $\mathbf{3 4 b}$, which structures were secured by X-ray analysis. A first oxidative coupling happens between the indole and the phenol to deliver the benzofuroindoline via phenolate iodobenzene $\mathbf{K}$. Then, 
exchange of an actetate of $\mathrm{Phl}(\mathrm{OAc})_{2}$ by the benzofuroindolinic nitrogen could lead to $\mathbf{L}$ which would be attacked by trifluoroethanol to produce a trifluoroethylarylether. A second addition of trifluoroethanol according to the same process via $\mathbf{M}$ delivers iminoquinone acetals $\mathbf{3 4 a}$ and $\mathbf{3 4 b}$.

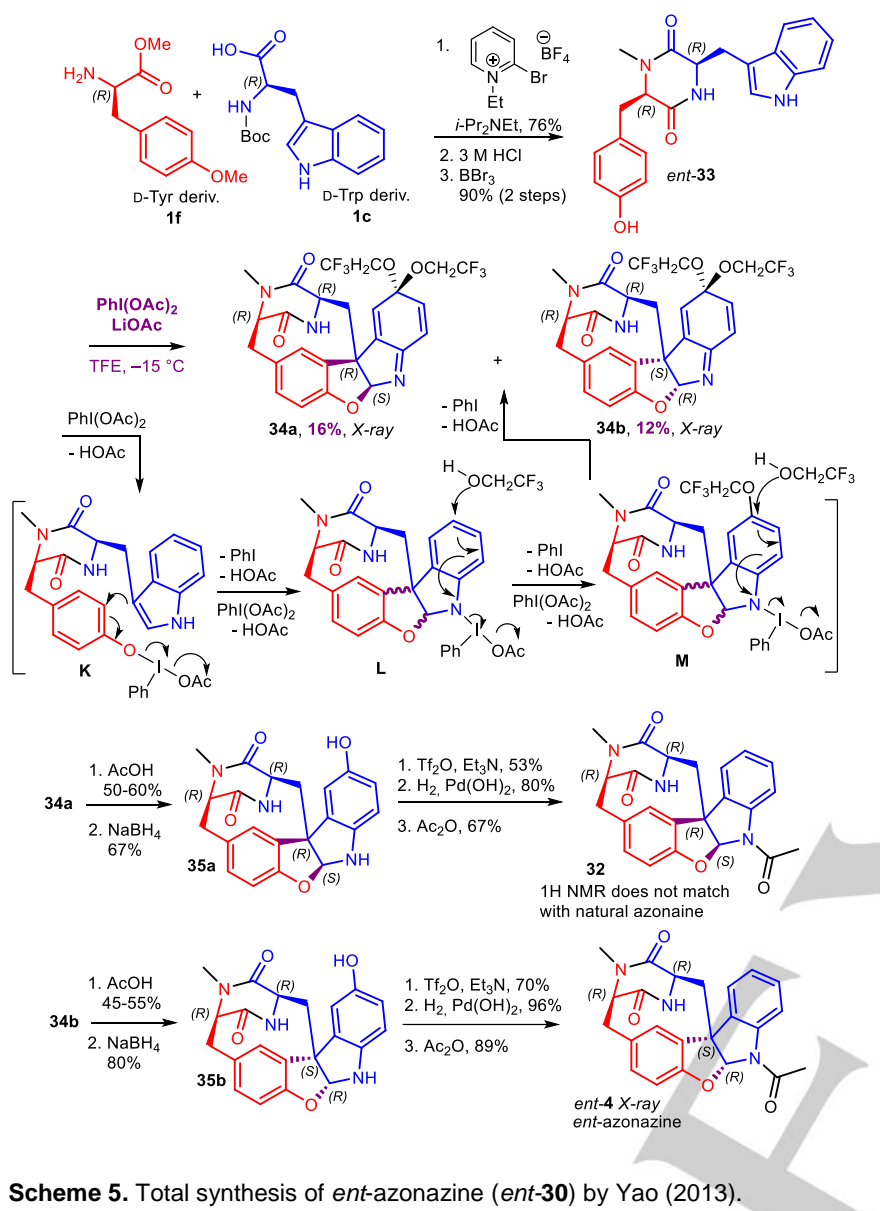

Hydrolysis of the acetal of $\mathbf{3 4 a}$ and reduction of the quinone delivered phenol 35a whose hydroxyl was removed by triflation and hydrogenation. $\mathrm{N}$-acetylation finally provided $\mathbf{3 2}$ whose structure was originally assigned to azonazine. However, NMR spectra of this compound did not match with the one of natural azonazine. The same sequence applied to $\mathbf{3 4 b}$ via $\mathbf{3 5 b}$ delivered a compound whose NMR spectra matched the ones of the natural product. However, the optical rotation was opposite to the one recorded for the natural product. Therefore, the authors have synthetized the enantiomer of azonazine (ent-4) and its structure was secured by $\mathrm{X}$-ray analysis.

The diazonamides and azonazine both possess a similar benzofuroindoline structure which arose from the oxidative cyclization of a peptidic precursor containing tyrosine and tryptophan units. However, the configuration of the stereogenic centers at the junction of the benzofurane and indole parts are opposite, despite the fact that these two natural products are both thought to be produced from the proteogenic amino acids Ltyrosine and L-tryptophan.

In 2015, we reported a diastereodivergent intermolecular coupling procedure between L-tyrosine and L-tryptophan derivatives to access both the stereochemistry of the diazonamides and azonazine at the quaternary center linking the indole and the phenol units (Scheme 6). ${ }^{[26]}$ This strategy employs the stereospecific addition of nucleophiles including arenes, ${ }^{[27]}$ to bromopyrroloindoline derivatives. Both diastereoisomeric exoand endo-bromopyrroloindolines 36 and 37 a were access by different bromination methods. Bisprotected L-tryptophan precursor $\mathbf{2 d}$ could be converted diastereoselectively into exobromopyrroloindoline $\mathbf{3 6}$ with the use of NBS, ${ }^{[28]}$ while endobromopyrroloindoline 37 a was accessed by acid-mediated cyclization of mono-protected L-tryptophan derivative $\mathbf{2 e}$ followed by a radical-mediated bromination with NBS in presence of AIBN followed by protection of the indoline nitrogen. ${ }^{[29]}$ In presence of soluble $\mathrm{AgSbF}_{6}$, pyrroloindolenium ions $\mathbf{N}$ and $\mathbf{O}$ are respectively formed from 36 and $37 \mathrm{a}$ with precipitation of $\mathrm{AgBr}$. Due to the existence of a stable two-membered cis-fused system in these cationic species, nucleophiles can add only on the open face and therefore this Friedel-Crafts-type reaction proceeds with retention of configuration. While free-phenol tyrosine derivative $\mathbf{1} \mathbf{b}$ only led to traces of the desired coupling products, O-methyl and O-allyl tyrosine $\mathbf{1 g}$ and $\mathbf{1 h}$ were efficiently added to 36 and $37 \mathrm{a}$ to respectively lead to $\mathbf{3 8 b}, \mathbf{c}$ with the stereochemistry of the diazonamides and $\mathbf{3 9 b , c}$ related to azonazine.

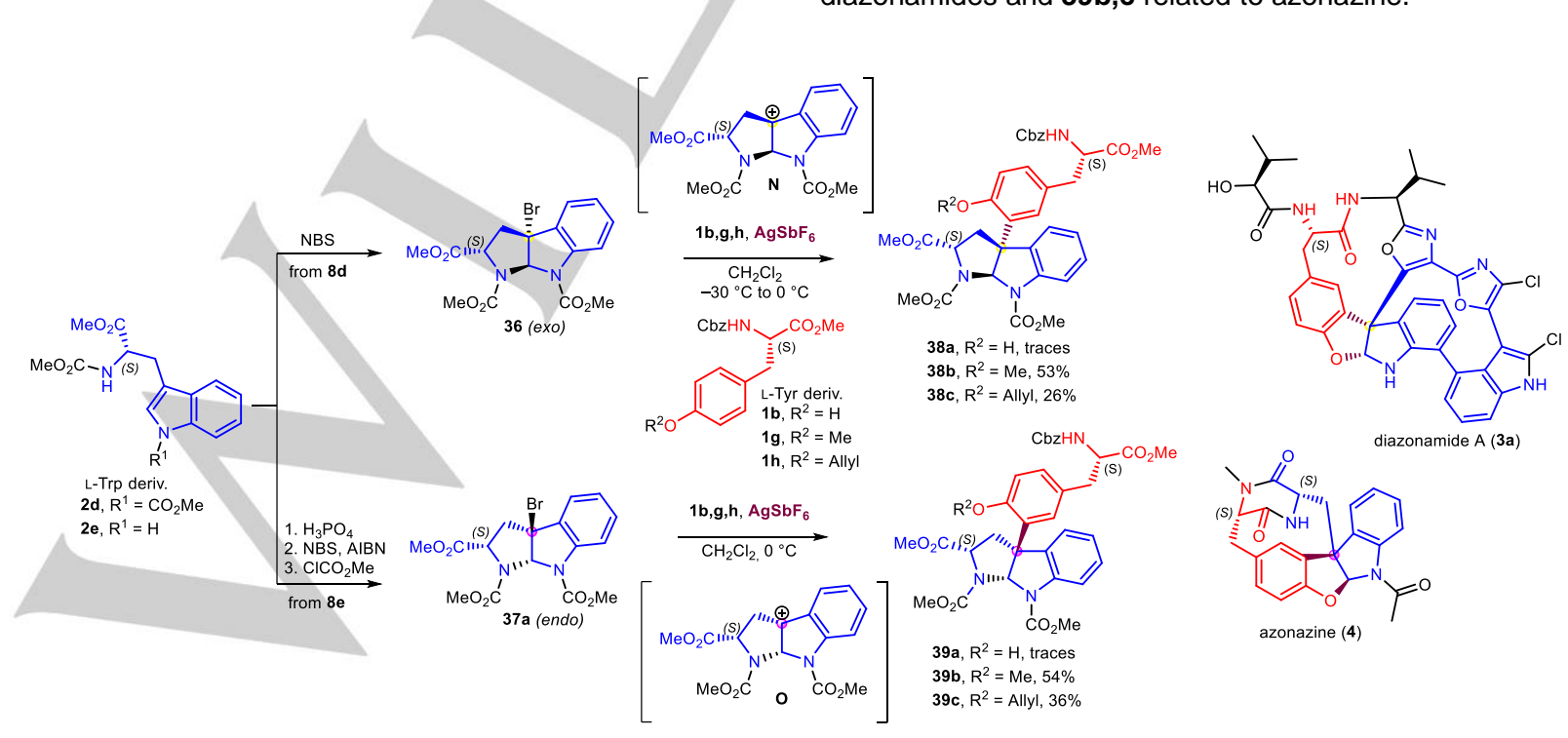




\section{Tryptorubin A}

Tryptorubin A (5) is of terrestrial origin unlike diazonamide A and azonazine. This natural product was isolated in 2017 by Clardy from a bacterial strain (Streptomyces sp. CLI2509) associated symbiotically to a fungus-growing ants (Hymenochaete rubiginosa). ${ }^{[30]}$ This bicyclic hexapeptide (Ala-Trp-Tyr-Ile-Trp-Tyr) which possesses two L-tryptophans (2a) and two L-tyrosines (1a), displays two unusual bonds: a $\mathrm{C}-\mathrm{N}$ bond between one of the tyrosine and one of the tryptophan units and a C-C bond between the two tryptophan units (Figure 5). In contrast to the diazonamides and azonazine, the biosynthetic oxidative coupling between the tyrosine and tryptophan units of tryptorubin A (5) did not resulted in the formation of a benzofuroindoline scaffold.
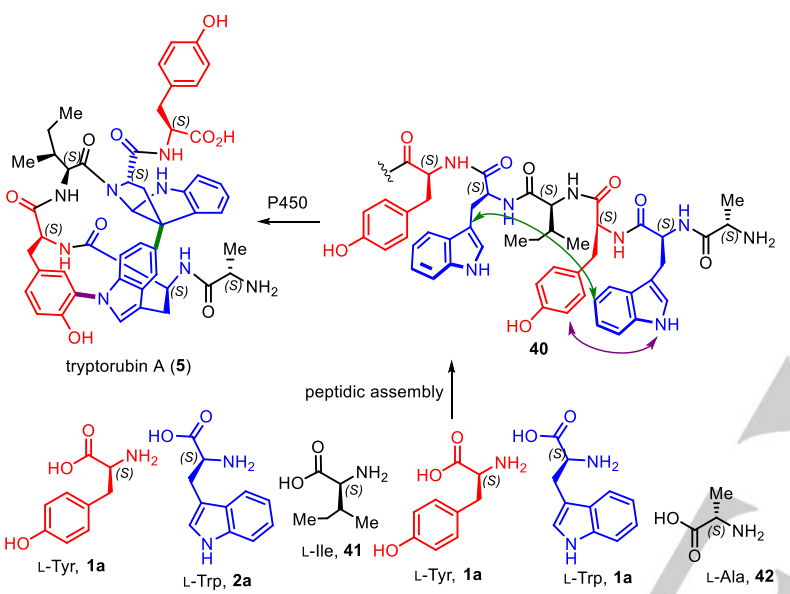

Figure 5. Structure and biosynthesis of tryptorubin A.

The tryptophan-tryptophan linkage connects the C3-position of one of the indole and the benzene ring of the other indole leading to a 3-arylated pyrroloindoline motif. Similar bonds between the C3 position and the benzene ring of two tryptophan units are found in dimeric diketopiperazine natural products such as naseseazines A-C, asperazine or pestalazine A (43a-e, Figure 6) which are biosynthetically produced by oxidative dimerisations mediated by P450 enzymes. ${ }^{[31]}$ More precisely, naseseazines A and $B$ display a C3-C7' bond, while asperazine and pestalazine $A$ present a C3-C8' bond. Only naseseazine C possess the C3-C6' connectivity encountered in tryptorubin $\mathrm{A}$.

The linkage between the internal tyrosine and the tryptophan already connected by its benzene ring is characterized by a bond between the ortho position of the phenol and the indolic nitrogen. Among natural products, only, the dimeric ergot alkaloid, cividiclavine, feature a bond between the ortho-position of a phenol and an indolic nitrogen. ${ }^{[32]}$
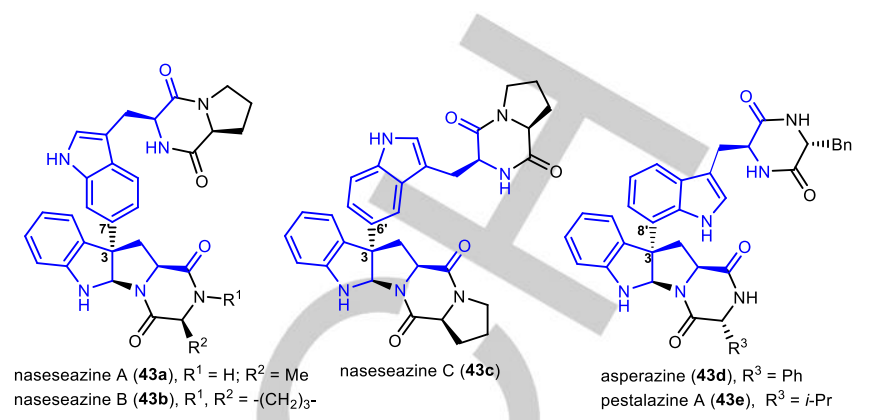

naseseazine $B(43 b), R^{1}, R^{2}=-\left(\mathrm{CH}_{2}\right)_{3}$ -

Figure 6. Structure of dimeric tryptophan-containing diketopiperazine related to tryptorubin A.

Tryptorubin A is believed to be a ribosomal synthesized and posttranslationally modified peptide (RiPP). Biosynthetically the unusual $\mathrm{C}-\mathrm{C}$ and $\mathrm{C}-\mathrm{N}$ bonds were probably formed by two intramolecular oxidative coupling mediated by a cytochrome P450 enzyme after assembly of the linear hexapeptidic chain $\mathbf{4 0}$ (Figure 4). ${ }^{[3]}$ Interestingly the terminal tyrosine is not involved in any oxidative coupling while one of the tryptophan is central to the two cyclisation events.

During their synthetic studies towards tryptorubin A, Baran and co-workers discovered that two non-canonical atropoisomers 4 and 44 could exist with the same connectivity and centralstereochemistry (Figure 7). ${ }^{[33]}$ The natural isomer 4 of tryptorubin $A$ is in the "bridge above" conformation, and its non-natural isomer 44 is in the "bridge below" conformation. The two compounds did not convert to each other at elevated temperature, indicating that the energy barrier between these two non-canonical atropisomers is high. Theoretically, the interconversion of the two isomers $\mathbf{4}$ and 44 requires a non-physical, inside-out flip of the molecule, allowing one macrocycle to pass through the other. If it is assumed that the bond can be extended beyond the covalent limit, then $\mathbf{4}$ and $\mathbf{4 4}$ can be interconverted. In other words, without breaking and reformatting the covalent bond, this conversion can hardly happen. Overall, it is in stark contrast to canonical atropisomerism and topoisomerism.
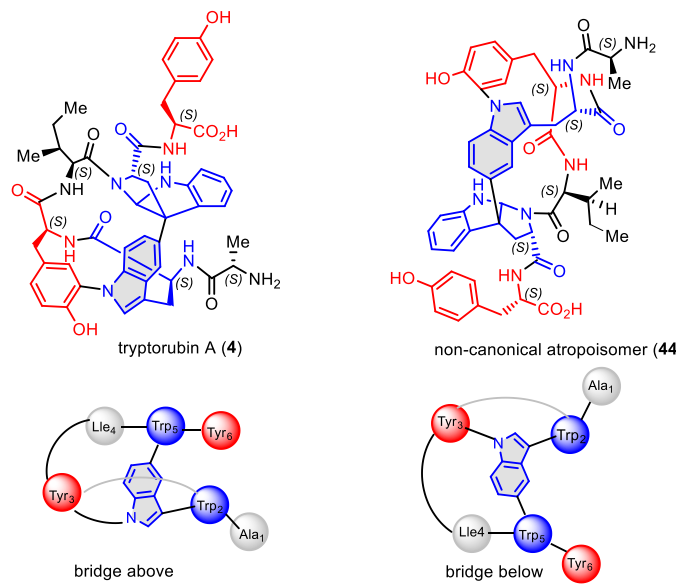

Figure 7. The conformation of the non-canonical atropoisomers of tryptorubin A 
Interestingly, before the discovery of tryptorubin A, the formation of a related tyrosine-tryptophan linkage was reported in 2014. During its synthetic studies toward azonazine, Yao investigated the use of electrochemistry to form the benzofuroindoline motif. Subjecting diketopiperazine ent-33 to a constant current (1.0 V vs SCE) in presence of sodium hydroxide as a base resulted unexpectedly to the formation of the $\mathrm{C}\left(\mathrm{sp}^{2}\right)-\mathrm{N}$ bond between the ortho-position of the phenol and the indolic nitrogen to generate a new 12-membered ring $\mathbf{4 5}$ similar to the one encountered in tryptorubin A (Scheme 7). ${ }^{[25 b]}$ The reaction presumably proceeds via single electron transfers from the indole and/or the phenol into radical intermediates.
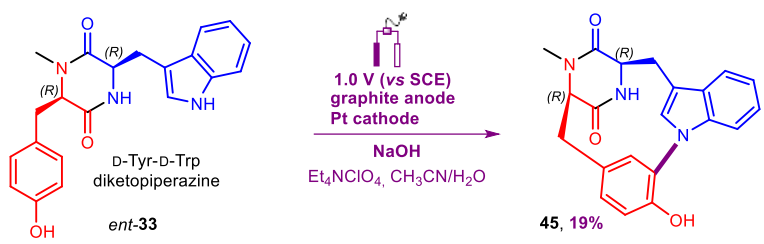

Scheme 7. Formation of a C-N bond by electrochemical oxidative cyclization of diketopiperazine ent-33 (2014)

In the other hand, bioinspired oxidative dimerizations of tryptophan derivatives have been developed in the context of the total synthesis of naseseazines $A, B$, asperazine or pestalazine $A$ (Scheme 8). ${ }^{[27 a, 27 b, 34-36]}$ For instance, Movassaghi described a two steps process in which diketopiperazine $\mathbf{4 6}$ is converted into bromopyrroloindoline $\mathbf{4 7}$ that is then involved in a Friedel-Crafts reaction in presence of $\mathrm{AgSbF}_{6}$ with another tryptophancontaining diketopiperazine $\mathbf{4 8}$ to deliver a mixture of regioisomeric arylated-pyrroloindolines 49.[27a,b] The regioselectivity could be controlled by the presence of a tetrafluoroborate on the nucleophilic entity but requires prefunctionalization (not shown). Alternatively, Ishikawa reported a direct biomimetic oxidation of L-tryptophan ester $\mathbf{2 f}$ with $\mathrm{Mn}(\mathrm{OAc})_{3}, \mathrm{VOF}_{3}$ or $\mathrm{V}_{2} \mathrm{O}_{5}$ in acidic conditions that deliver $\mathrm{C}_{3}-\mathrm{C}_{3}$ dimer $\mathbf{5 0}$ as well as the C3-C7' 51 dimer. ${ }^{[34]}$
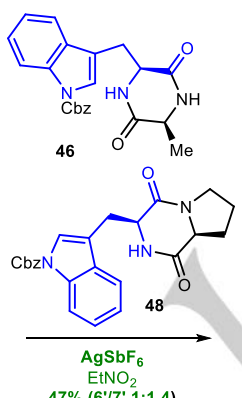

$47 \%\left(6^{\prime} / 77^{2} 1: 1.4\right)$
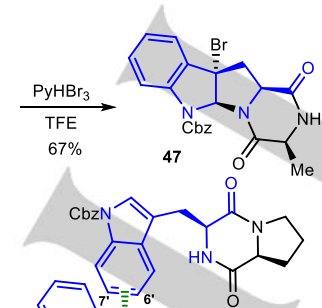

49

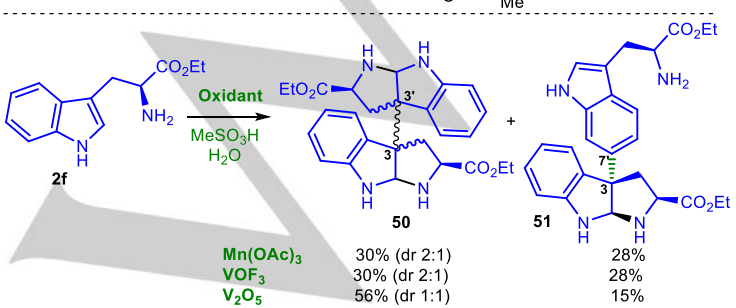

Scheme 8. C-C bond formation via bioinspired oxidative dimerizations of tryptophan derivatives by Movassaghi (top, 2011) and Ishikawa (bottom, 2013).
In 2020, Baran reported the first total synthesis of tryptorubin A (Scheme 9). When they started their synthetic endeavor, the authors were unaware of the possibility that the structure of tryptorubin A could exist as two non-canonical atropoisomers. Their retrosynthesis involved a late stage intramolecular peptidic coupling between the amine of the iso-leucine and the carboxylic acid of the internal tyrosine of $\mathbf{5 2}$. Inspired by the Movassaghi's total synthesis of the naseseazines, ${ }^{[27 a]}$ the $\mathrm{C}-\mathrm{C}$ bond between the two tryptophan residues would arise from an intermolecular Friedel-Crafts type reaction between tyrosine-containing endobromopyrroloindoline $\mathbf{5 3}$ and Tyr-Trp dipeptide $\mathbf{5 4}$ in which the C$\mathrm{N}$ bond is already formed.

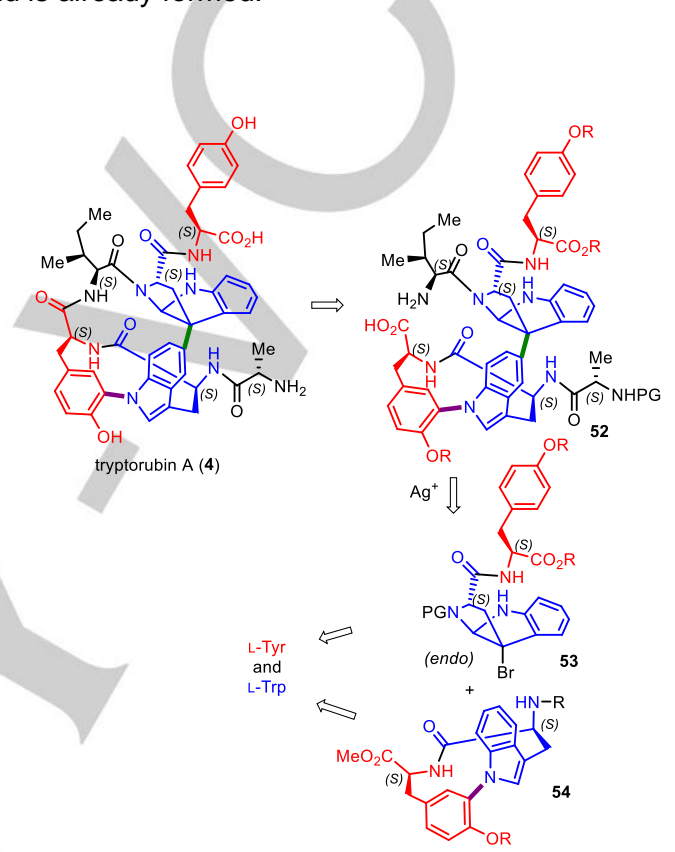

Scheme 9. Retrosynthesis of tryptorubin A by Baran (2020).

The authors adopted a non-biomimetic approach to form the C-N bond between the indole and the phenol (Scheme 10). An intramolecular Ullmann-Goldberg coupling with Buchwald-type conditions was applied to ortho-iodotyrosine-derived dipeptide 55 to yield 56 on a $20 \mathrm{~g}$ scale. ${ }^{[37]}$ To avoid $6^{\prime} / 7^{\prime}$ regioselectivity issues during the forthcoming Friedel-Crafts reaction, as observed by Movassaghi for the naseaseazines (see Scheme 8), the indole ring was reduced into indoline $\mathbf{5 7}$ with triethylsilane in order to increase the nucleophilicity of the position in para of the nitrogen. The alanine residue could also be appended before the reduction of the indole into 58. 


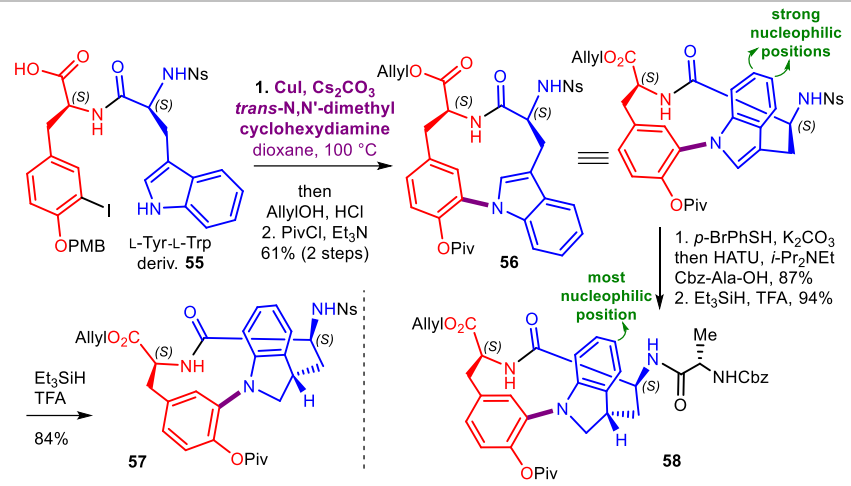

Scheme 10. C-N bond formation from a Tyr-Trp dipeptidic derivative by Baran (2020).

Endo-Bromopyrroloindoline $\mathbf{5 3}$ was obtained by acid mediatedcyclization of tryptophan derivative $\mathbf{2} \mathbf{g}$ followed by radicalbromination ${ }^{[26,29]}$ of $\mathbf{5 9}$ before coupling of $\mathbf{3 7 b}$ with tyrosine methyl ester 1i. Coupling of the latter with cyclic Tyr-Trp dipeptide $\mathbf{5 7}$ or 58 via the silver-mediated alkylation reaction established the key $\mathrm{C}-\mathrm{C}$ bond of $\mathbf{6 0}$ and $\mathbf{6 1}$ in a regioslective and stereoselective manner (Scheme 11). Oxidative aromatization of indoline 60 with
DDQ allowed to restore the indole ring. Then installation of alanine and iso-leucine residues extended the peptidic chain and gave hexamer $\mathbf{6 2}$ after deprotection. Final cyclization was then performed which led after deprotection with a total yield of $4 \%$ to 44 whose NMR data did not match natural tryptorubin A. The structure of this compound was attributed to atrop-tryptorubin A. The authors proposed that intermediate 62 have in equilibrium two conformers 62A and 62B via rotation around the enamine part of the indole. Since the second macrocycle has not been formed yet, this rotation is allowed. It is believed that the "ring-below" atropoisomer 62B is the most kinetically favourable conformation for the cyclisation process and therefore lead atroposelectively to 44.

The authors circumvented this problem by performing the aromatisation of the indoline after the macrocyclisation. The central chirality of the stereocenter on the indoline locked the "bridge above" conformation by structurally excluding the "bridge below" conformational isomer. After introduction of iso-leucine, the macrocyclisation of "bridge above" seco-acid 63A with PyAOP allowed to obtain atroposelectively isomer 64 which was converted to the natural product tryptorubin A (4) after oxidation of the indoline into the indole ring with DDQ and removal of the $\mathrm{Cbz}$ group and saponification of the methyl ester.

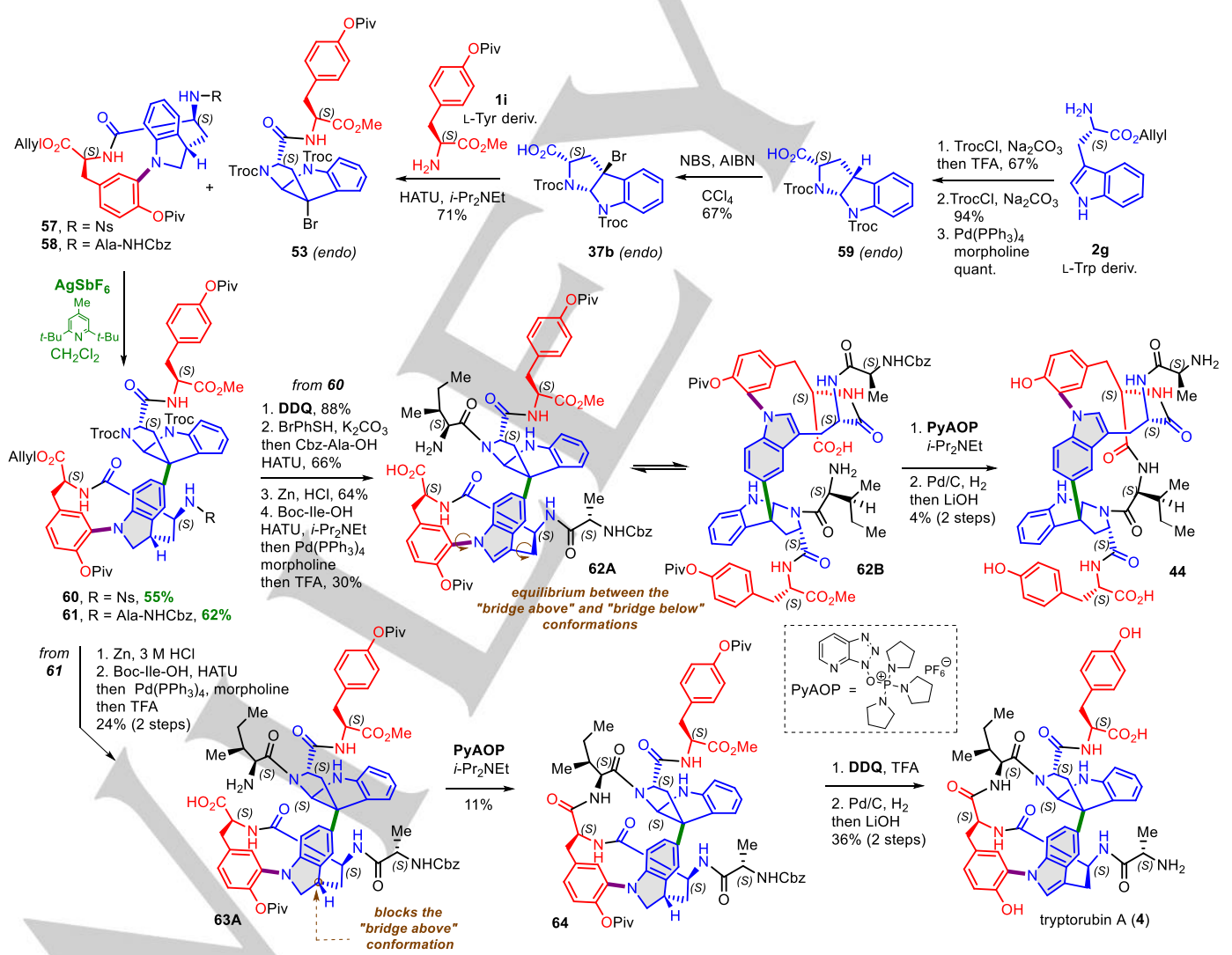

Scheme 11. Total synthesis of tryptorubin A and its non-canonical atropoisomer by Baran (2020).

\section{Concluding remarks}

In summary, we analyzed the biomimetic synthetic strategies towards diazonamide $A$, azonazine and tryptorubin $A$ via oxidative coupling of tyrosine and tryptophan residues of peptidic 
derivatives. It is apparent that accessing the benzofuroindoline core of diazonamide $\mathrm{A}$ and azonazine and its quaternary carbon has always been challenging. The development of phenol-indole oxidative coupling mediated by hypervalent iodine reagents allowed to overcome these difficulties and to perform the total synthesis of diazonamide A and azonazine. However, there is still room for innovation as demonstrated by the use of electrochemistry that improve the oxidative coupling process during the large scale production of DZ-2384, a simplified analog of diazonamide $\mathrm{A}$ with a high therapeutic potential as an antitumoral agent. Tryptorubin A differs from the diazonamides and azonazine by the fact that the biosynthetic oxidative coupling of tyrosine and tryptophan delivers a $\mathrm{C}-\mathrm{N}$ bond between the indolic nitrogen and the carbon of in the ortho-position of the phenol instead of a benzofuroindoline. The recent synthesis of tryptorubin A highlighted the highly unusual non-canonical atropoisomerism of this bicyclic hexapeptide which may inspired chemists in the design and analysis of complex three dimensional structures.

\section{Acknowledgements}

S.T. thanks the China Scholarship Council for a PhD fellowship. We thank Université Paris-Saclay and the CNRS for funding.

Keywords: tyrosine $\cdot$ tryptophan $\bullet$ oxidative coupling $\bullet$ natural products $\cdot$ bioinspired synthesis

[1] M.-C. Tang, Y. Zou, K. Watanabe, C. T. Walsh, Y. Tang. Chem. Rev. 2017, 117, 5226-5333

[2] a) J. Kohno, Y. Koguchi, M. Nishio, K. Nakao, M. Kuroda, R. Shimizu, T. Ohnuki, S. Komatsubara, J. Org. Chem. 2000, 65, 990-995; for a review: b) A. Coste, F. Couty, G. Evano, C. R. Chimie, 2008, 11, 1544-1573.

[3] a) S. Lin, S. J. Danishefsky, Angew. Chem. Int. Ed. 2002, 41, 512-515; b) M. Inoue, H. Sakazaki, H. Furuyama, M. Hirama, Angew. Chem. Int Ed. 2003, 42, 2654-2657; c) B. K. Albrecht, R. M. Williams, Org. Lett. 2003, 5, 197-200.

[4] a) Y. Yamada, T. Fujiwara, T. Sato, N. Igarashi, N. Tanaka, Nat. Struct. Biol. 2002, 9, 691-695; b) X. Carpena, S. Loprasert, S. Mongkolusk, J. Switala, P. C. Loewen, I. Fita, J. Mol. Biol. 2003, 327, 475-489.

[5] N. Lindquist, W. Fenical, G. D. VanDuyne and J. Clardy, J. Am. Chem. Soc. 1991, 113, 2303-2304

[6] J. Li, S. Jeong, L. Esser, P. G. Harran, Angew. Chem. Int. Ed. 2001, 40, 4765-4769.

[7] J. Li, A. W. G. Burgett, L. Esser, C. Amezcua, P. G. Harran, Angew. Chem. Int. Ed. 2001, 40, 4770-4773.

[8] bipleiophylline: a) T.-S. Kam, S.-J. Tan, S.-W. Ng, K. Komiyama, Org Lett. 2008, 10, 3749-3752; pleiocraline: b) B. C. Das, J. P. Cosson, G Lukacs, J. Org. Chem. 1977, 42, 2785-2786; pleiocorine: c) B. C. Das, J. P. Cosson, G. Lukacs, Potier, P. Tetrahedron Lett. 1974, 15, 4299-4302.

[9] For reviews on the synthesis of benzofuroindolines: a) Ito, Y.; Ueda, M.; Miyata, O. Heterocycles, 2014, 89, 2029-2052; b) Beaud, R.; Tomakinian, T.; Denizot, N.; Pouilhès, A.; Kouklovsky, C.; Vincent, G. Synlett, 2015, 26, 432-440.

[10] R. Fernández, M. J. Martín, R. Rodríguez-Acebes, F. Reyes, A. Francesch, C. Cuevas, Tetrahedron Lett. 2008, 49, 2283-2285.

[11] a) K. C. Nicolaou, M. Bella, D. Y.-K. Chen, X. Huang, T. Ling, S. A. Snyder, Angew. Chem. Int. Ed. 2002, 41, 3495-3499; b) K. C. Nicolaou, D. Y.-K. Chen, X. Huang, T. Ling, M. Bella, S. A. Snyder, J. Am. Chem. Soc. 2004, 126, 12888-12896.

[12] C.-M. Cheung, F. W. Goldberg, P. Magnus, C. J. Russell, R. Turnbull, V. Lynch, J. Am. Chem. Soc. 2007, 129, 12320-12327.

[13] A. W. G. Burgett, Q. Y. Li, Q. Wei, P. G. Harran, Angew. Chem. Int. Ed. 2003, 42, 4961-4966.
[14] The group of Moody was able to perform an oxidative cyclization of a tetrapeptide related to $\mathbf{1 1}$ to form the bis-oxazole moiety but without forming the benzofuroindoline and the biaryl bond: a) J. Sperry, C. J. Moody, Chem. Commun. 2006, 2397-2399; b) J. Sperry, C. J. Moody, Tetrahedron 2010, 66, 6483-6495.

[15] For other examples of synthesis of benzofuroindolines with hypervalent iodine reagents: a) Chan, C.; Li, C.; Zhang, F.; Danishefsky, S. J. Tetrahedron Lett. 2006, 47, 4839-4841; b) Nicolaou, K. C.; Majumder, U.; Roche, S. P.; Chen, D. Y.-K.. Angew. Chem. Int. Ed. 2007, 46, 47154718; d) Li, L.; Yuan, K.; Jia, Q.; Jia, Y. Angew. Chem. Int. Ed. 2019, 58 6074-6078; for other selected bioinspired synthesis of benzofuroindolines: e) W. Tian, L. Rao Chennamaneni, T. Suzuki, D. Y.K. Chen, Eur. J. Org. Chem. 2011, 1027-1031; f) R. Beaud, R. Guillot, C. Kouklovsky, G. Vincent, Angew. Chem. Int. Ed. 2012, 51, 12546-12550; g) L.; Liao, C.; Shu, M. Zhang, Y. Liao, X.-Y. Hu, Y. Zhang, Z. Wu, W. Yuan, X.-M. Zhang, Angew. Chem. Int. Ed. 2014, 53, 10471-10475; h) T. Tomakinian, R. Guillot, C. Kouklovsky, G. Vincent, Angew. Chem. Int. Ed. 2014, 53, 11881-11885; i) N. Denizot, A. Pouilhès, M. Cucca, R. Beaud, R. Guillot, C. Kouklovsky, G. Vincent, Org. Lett. 2014, 16, 5752-5755; j) D. Lachkar, N. Denizot, G. Bernadat, K. Ahamada, M. A. Beniddir, V. Dumontet, J.-F. Gallard, R. Guillot, K. Leblanc, E. O. N'nang, V. Turpin, C. Kouklovsky, E. Poupon, L. Evanno, G. Vincent, Nat. Chem. 2017, 9, 793-798; k) Liu, K.; Tang, S.; Huang, P.; Lei, A. Nat. Commun. 2017, 8 775.

[16] a) K. C. Nicolaou, J. Hao, M. V. Reddy, P. B. Rao, S. A. Snyder, G. Rassias, X. Huang, D. Y.-K. Chen, Angew. Chem. Int. Ed. 2003, 42 1753-1758; b) K. C. Nicolaou, J. Hao, M. V. Reddy, P. B. Rao, G. Rassias, S. A. Snyder, X. Huang, D. Y.-K. Chen, W. E. Brenzovich, N. Giuseppone, P. Giannakakou, A. O'Brate, J. Am. Chem. Soc. 2004, 126, 12897 12906; c) C.-K. Mai, M. F. Sammons, T. Sammakia, Angew. Chem. Int. Ed. 2010, 49, 2397-2400; d) R. R. Knowles, J. Carpenter, S. B. Blakey, A. Kayano, I. K. Mangion, C. J. Sinz, D. W. C. MacMillan, Chem. Sci. 2011, 2, 308-311; e) N. David, R. Pasceri, R. R. A. Kitson, A. Pradal, C J. Moody, Chem. Eur. J. 2016, 22, 10867-108776.

[17] For a review: M. Lachia, C. J. Moody, Nat. Prod. Rep. 2008, 25, 227-253.

[18] J. Lin, B. S. Gerstenberger, N. Y. T. Stessman, J. P. Konopelski, Org Lett., 2008, 18, 3969-3972;

[19] a) Z. Cruz-Monserrate, H. C. Vervoort, R. Bai, D.J. Newman, S. B Howell, G. Los, J. T. Mullaney, M. D. Williams, G. R. Pettit, W. Fenical, E. Hamel, Mol. Pharmacol. 2003, 63, 1273-1280; b) G. Wang, L. Shang, A. W. G. Burgett, P. G. Harran, X. Wang, Proc. Natl. Acad. Sci. U.S.A 2007, 104, 2068-2073

[20] N. S. Williams, A. W. G. Burgett, A. S. Atkins, X. Wang, P. G. Harran, S L. McKnight, Proc. Natl. Acad. Sci. U.S.A. 2007, 104, 2074-2079.

[21] a) G. Hanson, C. Caldwell, P.G. Harran, S. Harran, Q. Wei, M. Zhou, US 7,851,620 B2, 2010; b) Harran, P. G.; Williams, N.; Burgett, A. US 7,538,129 B2, 2009

[22] a) M. Wieczorek, J.Tcherkezian, C. Bernier, A. E. Prota, S. Chaaban, Y Rolland, C. Godbout, M. A. Hancock, J. C. Arezzo, O. Ocal, C. Rocha, N. Olieric, A. Hall, H. Ding, A. Bramoullé, M. G. Annis, G. Zogopoulos, P. G. Harran, T. M. Wilkie, R. A. Brekken, P. M. Siegel, M. O. Steinmetz G. C. Shore, G. J. Brouhard, A. Roulston, Sci. Transl. Med. 2016, 8, 365 159; b) C. Bernier, A. Soliman, M. Gravel, M. Dankner, P. Savage, K. Petrecca, M. Park, P. M. Siegel, G. C. Shore, A. Roulston, Anticancer Drugs 2018, 29, 774-785.

[23] H. Ding, P. L. DeRoy, C. Perreault, A. Larivée, A. Siddiqui, C. G. Caldwell, S. Harran, and P. G. Harran, Angew. Chem. Int. Ed. 2015, 54, 4818-4822.

[24] Q. X. Wu, M. S. Crews, M. Draskovic, J. Sohn, T. A. Johnson, K. Tenney, F. A. Valeriote, X. J. Yao, L. F. Bjeldanes, P. Crews, Org. Lett. 2010, 12 4458-4461.

[25] a) J. C. Zhao, S. M. Yu, Y. Liu, Z. J. Yao, Org. Lett. 2013, 15, 4300-4303 b) J. C. Zhao, S. M. Yu, H. B. Qu, Z. J. Yao, Tetrahedron. 2014, 70, 3197-3210.

[26] N. Denizot, R. Guillot, C. Kouklovsky, G. Vincent, Chem. Eur. J. 2015 21, 18953-18956.

[27] a) J. Kim, M. Movassaghi, J. Am. Chem. Soc. 2011, 133, 14940-14943; b) R. Loach, O. S. Fenton, M. Movassaghi, J. Am. Chem. Soc. 2016, 138, 1057-1064; c) Boyer, M. Movassaghi, Chem. Sci. 2012, 3, 1798-1803; d) A. Coste, J. Kim, T. C. Adams, M. Movassaghi, Chem. Sci. 2013, 4 
3191-3197; e) Y. Wang, C. Kong, Y. Du, H. Song, D. Zhang, Y. Qin, Org. Biomol. Chem. 2012, 10, 2793-2797.

[28] C. S. Lopez, C. Perez-Balado, P. Rodriguez-Grana, A. R. de Lera, Org. Lett. 2008, 10, 77-80.

[29] a) M. Movassaghi, O. K. Ahmad, S. P. Lathrop, J. Am. Chem. Soc. 2011 133, 13002-13005; b) M. Bruncko, D. Crich, R. Samy, J. Org. Chem. 1994, 59, 5543-5549.

[30] T. P. Wyche, A. C. Ruzzini, L. Schwab, C. R. Currie, J. Clardy, J. Am. Chem. Soc. 2017, 139, 12899-12902.

[31] a) W. Tian, C. Sun, M. Zheng, J. R. Harmer, M. Yu, Y. Zhang, H. Peng, D. Zhu, Z. Deng, S.-L. Chen, M. Mobli, X. Jia, X. Qu, Nat. Commun. 2018, 9, 4428; b) H. Yu, S.-M. Li, Org. Lett. 2019, 21, 7094-7098.

[32] L. C. Vining, A. G. Mcinnes, D. G. Smith, J. L. C. Wright, W. A. Taber, FEMS Symp. 1982, 13, 243-251.

[33] S. H. Reisberg, Y. Gao, A. S. Walker, E. J. N. Helfrich, J. Clardy, P. S. Baran, Science 2020, 367, 458-463

[34] a) S. Tadano, Y. Mukaeda, H. Ishikawa, Angew. Chem. Int. Ed. 2013, 52, 7990-7994; b) S. Tadano, Y. Sugimachi, M. Sumimoto, S. Tsukamoto, H. Ishikawa, Chem. Eur. J. 2016, 22, 1277-1291.

[35] For a review: S. Tadano, H. Ishikawa, Synlett, 2014, 25, 157-162.

[36] For other selected syntheses: a) S. P. Govek, L. E. Overman, J. Am. Chem. Soc. 2001, 123, 9468-9469; b) S. P. Govek, L. E. Overman Tetrahedron 2007, 63, 8499-8513; c) M. E. Kieffer, K. V. Chuang, S. E. Reisman, J. Am. Chem. Soc. 2013, 135, 5557-5560; d) X. Wang, G. Ma, Y. Peng, C. E. Pitsch, B. J. Moll, T. D. Ly, X. Wang, H. Gong, J. Am Chem. Soc. 2018, 140, 14490-14497; e) L. Luo, X.-Y. Zhai, Ya-W. Weng, Y. Peng, H. Gong, Chem. Eur. J. 2019, 25, 989-992.

[37] K. Kunz, U. Scholz, D. Ganzer, Synlett 2003, 15, 2428-2439. 


\section{Entry for the Table of Contents}

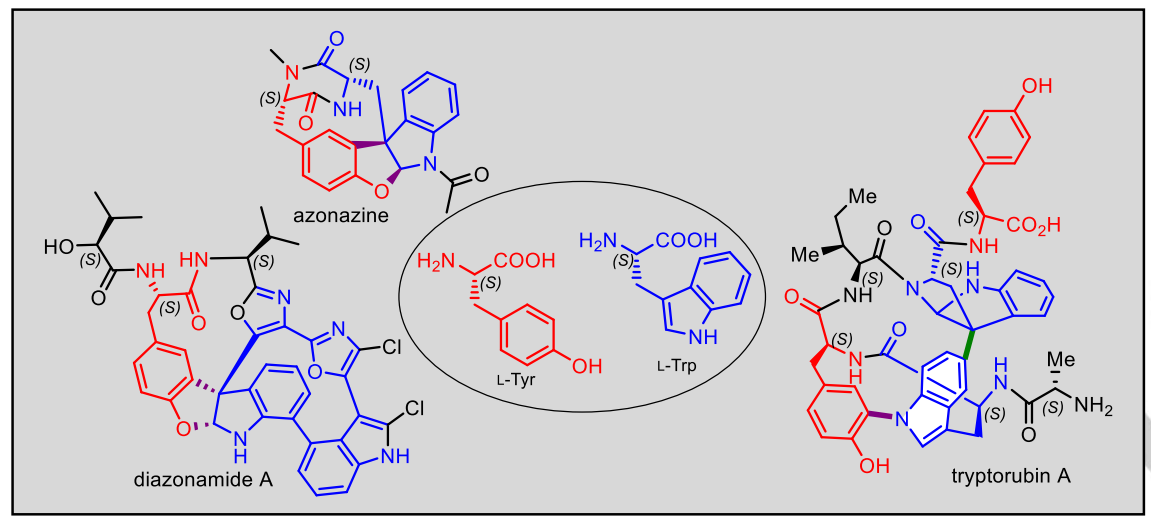

We review the oxidative coupling of tyrosine and tryptophan units as a pivotal step in the total synthesis of some peptide-derived natural products such as diazonamide $\mathrm{A}$, azonazine and tryptorubin $\mathrm{A}$.

@GVincentUPSUD 